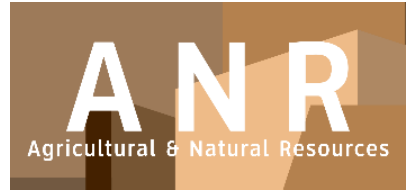

PAPER - OPEN ACCESS

Pengaruh Kondisi Internal Pertanian Terhadap Sistem Pertanian Terintegrasi Padi Sawah dengan Ternak Kerbau dan Pengembangan Wilayah di Kabupaten Humbang Hasundutan
Author
: Hotden L Nainggolan
DOI
: 10.32734/anr.v1i2.227
Electronic ISSN
: 2654-7023
Print ISSN
: 2654-7015

Volume 1 Issue 2-2018 TALENTA Conference Series: Agricultural \& Natural Resources (ANR)

This work is licensed under a Creative Commons Attribution-NoDerivatives 4.0 International License.

Published under licence by TALENTA Publisher, Universitas Sumatera Utara
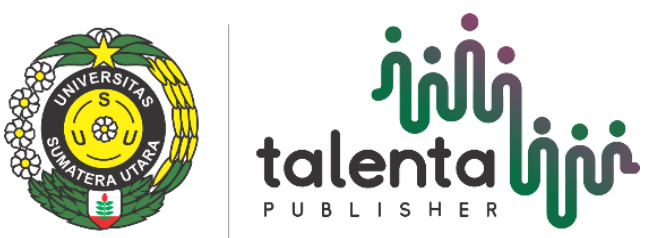


\title{
Pengaruh Kondisi Internal Pertanian Terhadap Sistem Pertanian Terintegrasi Padi Sawah dengan Ternak Kerbau dan Pengembangan Wilayah di Kabupaten Humbang Hasundutan
}

\author{
Hotden L. Nainggolan ${ }^{\mathrm{b}}$, Marlon Sihombing ${ }^{\mathrm{a}}$, Tavi Supriana ${ }^{\mathrm{a}}$, Ma'ruf Tafsin ${ }^{\mathrm{a}}$ \\ ${ }^{a}$ Universitas Sumatera Utara, Medan 20155, Indonesia \\ ${ }^{b}$ Universitas HKBP Nommensen, Medan, Indonesia
}

hotdenleonardo76@gmail.com,hotden_ngl@yahoo.com

\begin{abstract}
Abstrak
Penelitian ini bertujuan mengetahui pengaruh kondisi internal pertanian terhadap sistem pertanian terintegrasi padi sawah dengan ternak kerbau dan pengembangan wilayah di Kabupaten Humbang Hasundutan. Metode analisis dengan R/C ratio dan pemodelan persamaan struktural (Structural Equation Modeling). Hasil penelitian; a) sistem pertanian terintegrasi padi sawah dan ternak kerbau lebih efisien dibandingkan usahatani non integrasi (R/C integrasi 2,4795 > R/C non-integrasi), b) Kondisi internal pertanian berpengaruh positif signifikan terhadap sistem pertanian terintegrasi dengan bobot regresi standar $0.52, \mathrm{p}<0.001, \mathrm{c}$ ) Kondisi internal pertanian berpengaruh langsung tidak signifikan terhadap pengembangan wilayah dengan bobot regresi standar $0.24, \mathrm{p}<0.001$; c) Kondisi internal pertanian berpengaruh tidak langsung terhadap pengembangan wilayah melalui sistem pertanian terintegrasi padi sawah dan ternak kerbau sebesar 0.28 , total pengaruh kondisi internal pertanian terhadap pengembangan wilayah sebesar 0.52. Berdasarkan hasil penelitian disarankan agar: a) pemerintah daerah melakukan pelatihan kepada petani yang mengelola pertanian sistem integrasi agar lebih baik, b) pemerintah memperhatikan kelanyakan sarana prasarana pertanian, khususnya fasilitas jalan, irigasi, c) pemerintah menyediakan bibit berkualitas, penyuluhan tentang beternak yang baik, d) pemerintah melakukan pelatihan terhadap petani dalam mengembangkan usahataninya sehingga pendapatan meningkat dan berdampak pada pengembangan wilayah, e) pemerintah membantu petani untuk mendapatkan modal usahatani yang lebih fleksibel dan harga output yang stabil.
\end{abstract}

Kata Kunci: kondisi internal; sistem integrasi; padi sawah; pendapatan; pengembangan wilayah

\section{Pendahuluan}

Sektor pertanian memiliki peran penting dalam pembangunan daerah, sebagai penyerap tenaga kerja, penghasil makanan pokok, stabilitas harga pasar, pendorong ekspor dan sebagai bahan industri manufaktur. Pengembangan wilayah merupakan suatu proses yang dimaksudkan untuk melakukan perubahan menuju perkembangan masyarakat yang lebih baik, dengan memanfaatkan berbagai sumber daya seperti sektor pertanian Borisov [1] dan Baransano [2].

Pembangunan pertanian dapat dilakukan melalui; intensifikasi, ekstensifikasi, diversifikasi dan rehabilitasi secara terpadu untuk meningkatkan pendapatan petani. Pembangunan pertanianmemiliki keterkaitandengan faktor fisik; tataguna lahan, pemupukan, bibit, budidaya tanaman, proteksi tanaman. Faktor sosial; tenaga kerja, tingkat 
pendidikan petani dan kelembagaan. Faktor ekonomi; modal, pendapatan keluarga petani, suku bunga, inflasi dan faktor pembangunan; fasilitas jalan dan irigasi (pengairan).

Kebijakan pembangunan pertanian bertujuanmeningkatkan kapasitas petani melalui rumusan pembangunan pertanianyaitu;

- $\quad$ peningkatan pendapatan dan taraf hidup melalui pengembangan sistem agribisnis

- pengembangan aktivitas agribisnis yang berdaya saing dan berkelanjutan

- mewujudkan sistem ketahanan panganberbasis keragaman dan budaya pangan lokal

- meningkatkan kesempatan kerja dan berusaha melalui pengembangan agribisnisSetyowati [3].

Sektor pertanian memiliki peran penting bagi Kabupaten Humbang Hasundutan. Sektor ini mampu memberikan kontribusi 52,79\% tahun 2012, dan 53,6 \% tahun 2014 terhadap PDRB wilayah ini, dengan rata-rata laju pertumbuhan 3,83\% tahun 2009-2014 BPS Humbang Hasundutan Dalam Angka [4].

Pola pengelolaan usahatani yang dilakukan masyarakat untuk meningkatkan pendapatannya di Kabupaten Humbang Hasundutan, secara umum masih bersifat subsistem dengan memanfaatkan tenaga kerja dalam keluarga dengan modal yang terbatas, dengan pola pengelolaan sesuai dengan kearifan lokal Nainggolan [5].

Usahatani ini dikelola sesuai dengan konsep pertanian integrasi antara usaha tani padi sawah sebagai core usaha dengan ternak kerbau dalam skala rumah tangga. Sistem ini merupakan pertanian yang dikelola secara turun temurun sebagai suatu kearifan lokal. BPS Humbang Hasundutan Dalam Angka [4] menunjukkan petani yang mengusahakan komoditi padi sawah terpadu dengan usaha peternakan kerbau berjumlah $8.937 \mathrm{kk}$, atau 21,91\% dari $40.783 \mathrm{kk}$ penduduk daerah ini dan tersebar pada 10 kecamatan.

Bijttebier[6] menyampaikan sistem pertanian terintegrasi (SPT) merupakan sistem pengelolaan tanaman, hewan ternak dan ikan untuk menghasilkan suatu produk secara optimal. Anugrah [7] menyampaikan sistem pertanian terintegrasi (SPT) memiliki keuntungan baik dari sisi aspek ekologi maupun ekonomi, yaitu; usahatani ramah lingkungan,hemat energi, usahatani lebih diversifikatif, diversifikasi produk lebih tinggi dan serapantenaga kerja lebih baik.

Untuk mendukung sistem pertanian terintegrasi padi sawah dan ternak kerbau di wilayah ini didasari untuk meningkatkan pendapatan. Parma [8] menyampaikan kekuatan petani untuk meningkatkan pendapatannya, adalah ; a) motivasi petani dalam berusahatanipadidan keinginan meningkatkan pendapatannya, b) pengalaman petani dalam mengelola usahatani padi, c) ketersediaan tenaga kerja dalam keluarga.

BPS Humbang Hasundutan [4] menunjukkan laju pertumbuhan produktifitas komoditi padi sawah di Kabupaten Humbang Hasudutan mengalami fluktuasi pada tahun 2009-2012. Tahun 2009 laju pertumbuhan produktifitas 1,0\%, naik menjadi 1,48\% tahun 2010 dan turun menjadi 0,10\% pada tahun 2011 kemudian naik 0,60\% tahun 2012, dengan rata-rata laju pertumbuhan $0,80 \%$ dan lebih kecil dibanding rata-rata laju pertumbuhan produktifitas padi Sumatera Utara yaitu 2,14\% BPS Sumatera Utara [9], dengan demikian diperlukan perencanaan pertanian yang lebih komprehensip sesuai dengan potensi dan kondisi agroekologis wilayah dalam rangka meningkatkan pendapatan petani di Kabupaten Humbang Hasundutan, maka tujuan penelitian ini adalah untuk; a) mengetahui efisiensi sistem pertanian terintegrasi padi sawah dengan ternak kerbau; b) mengetahui pengaruh kondisi internal pertanian terhadap sistem pertanian terintegrasi padi sawah dengan ternak kerbau,c) mengetahui pengaruh sistem pertanian terintegrasi padi sawah dengan ternak kerbau terhadap pengembangan wilayah dan; d) mengetahui pengaruh kondisi internal pertanian terhadap pengembangan wilayah di Kabupaten Humbang Hasundutan melalui sistem pertanian terintegrasi padi sawah dan ternak kerbau. 


\section{Metode Penelitian}

\subsection{Lokasi Penelitian}

Penelitian dilakukan di Kabupaten Humbang Hasundutan yang ditentukan purphosive, dan daerah potensial untuk pengembangan sektor pertanian. Populasi penelitian ini berjumlah $8.937 \mathrm{kk}$ yaitu petani padi sawah yang memelihara ternak kerbau dalam skala rumah tangga dan tersebar pada 10 kecamatan yaitu; Kecamatan Pakkat (1.663 kk), Onan Ganjang (708 kk), Sijamapolang (233 kk), Doloksanggul (1.456 kk), Lintong Nihuta (1.150 kk), Paranginan (560 kk), Baktiraja (152 kk), Pollung (1.242 kk), Parlilitan (1.342 kk) dan Tarabintang (428 kk)BPS Humbang Hasundutan[4] . Sampel penelitian ditentukan dengan menggunakan formula Slovin;

$$
n_{\mathrm{c}}=\frac{N}{1+N e^{2}}
$$

dimana; $\mathrm{n}_{\mathrm{c}}=$ ukuran sampel, $\mathrm{e}=$ interval kesalahan $(0,1), \mathrm{N}=$ Jumlah populasi.

Jumlah sampel yang diperoleh 99,98 dibulatkan 100 sampel. Sampel yang diwawancarai setiap kecamatan ditentukan secara proporsional, dengan perincian; Kecamatan Pakkat (19 responden), Onan Ganjang (8 responden), Sijamapolang (3 responden), Doloksanggul (16 responden), Lintong Nihuta (13responden), Paranginan (6 responden), Baktiraja (2 responden), Pollung (14 responden), Parlilitan (15 responden) dan Tarabintang (5 responden).

\subsection{Jenis dan Sumber Data serta Variabel Penelitian}

Data yang digunakan dalam penelitian ini adalah data primer diperoleh dari lapangan melalui wawancara dengan menggunakan kuisioner. Data sekunder diperoleh dari publikasi Badan Pusat Statistik (BPS) Kabupaten Humbang Hasundutan, hasil-hasil penelitian, jurnal dan publikasi resmi lainnya.

Variabel yang dianalisis yaitu; a) variabel laten eksogen kondisi internal pertanian (X1) dengan 5 indikator (variabel terukur); luas lahan (X1.1); topografi (X1.2); tataguna lahan (X1.3); fasilitas jalan (X1.4); pengalaman bertani (X1.5); b ) Variabel laten endogen sistem pertanian terintegrasi (Y1) dengan 3 indikator (variabel terukur); peningkatan pendapatan (Y1.1); peningkatan ketahanan pangan (Y1.2); pelestarian budaya (Y1.3); c) Variabel laten endogen pengembangan wilayah (Y2) dengan 4 indikator (variabel terukur); penyediaan lingkungan kondusif (Y2.1); pengurangan dampak lingkungan (Y2.2); pengurangan kemiskinan (Y2.3); peningkatan akses pasar (Y2.4).

\subsection{Metode Analisis Data}

Metode analisis data adalah; a) untuk mengetahui efisiensi sistem pertanian terintegrasi padi sawah dengan ternak kerbau, dianalisis dengan R/C-ratio, kriteria; R/C $\square 1$ usahatani layak, R/C = 1 BEP (titik impas) dan R/C < 1 usahatani tidak layak, b) untuk menganalisis pengaruh kondisi internal pertanian terhadap sistem pertanian terintegrasi padi sawah dan ternak kerbau dan pengembangan wilayah di Kabupaten Humbang Hasundutan dianalisis dengan pemodelan persamaan structural (Structural Equation Modelling/SEM) dengan menggunakan perangkat lunak IBM® SPSS $®$ Amos 22.

Proses pemodelan dalam penelitian ini melalui beberapa langkahShek and Yu [10], yaitu; 1) Spesifikasi model dengan menetapkan model hipotesis berdasarkan literature/ buktiempiris; 2) Identifikasi model, untukvariabel endogen, suku galat dibuat dengan bobot regresi untuk setiap suku galat yang ditetapkan sama dengan 1. Jika menggunakan variabel laten lebih dari satu indikator, bobot regresi paling sedikit satu jalur harus ditetapkansebesar 1. 3) Estimasi model (bagian 1). Analisis setiap model pengukuran.Modifikasi/ pertahankan model awal dengan memperhatikan kecocokan model dan indeks modifikasi.4) Estimasi model-(bagian 2). Analisis keseluruhan model struktural.5) Evaluasi model. Evaluasi goodness-of-fit dari keseluruhan model. 6) Modifikasi model. Respesifikasi 
model berdasarkan kecocokanmodel jika hasilnya tidak berada dalam jangkauan yang dapatditerima atau pertahankan model hipotesis berdasarkan indeks kecocokan model.

Dalam penelitian ini, untuk mengurangi bias ukuran sampel, digunakan penilaian kecocokan keseluruhan dari model. Kriteria kecocokan untuk model pengukuran dan model structural (Tabel 1).

Tabel.1. Kriteria Kecocokan Model Pengukura dan Model Struktural.

\begin{tabular}{|c|c|c|c|}
\hline Ukuran & Defenisi/ deskripsi & $\begin{array}{l}\text { Tingkat kecocokan yang bisa } \\
\text { Diterima }\end{array}$ & Keterangan \\
\hline Chi-Square & & $\begin{array}{l}\text { Semakin kecil } \\
(p \text {-value } \geq 0,05)\end{array}$ & Semakin baik \\
\hline$R M R$ & $\begin{array}{l}\text { Root mean square residual (nilai rata-rata } \\
\text { semua residual yang ditandarisasi) }\end{array}$ & $R M R \leq 0.05$ & Baik \\
\hline$C_{I}$ & Goodness of fit index (nilai indeks & $G F I \geq 0.90$ & Baik \\
\hline GFI & keselarasan) & $0.80 \leq G F I<0.90$ & Cukup baik \\
\hline$N F I$ & Normed fit index (indeks kecocokan) & $\begin{array}{l}N F I \geq 0.90 \\
0.80 \leq N F I<0.90\end{array}$ & $\begin{array}{l}\text { Baik } \\
\text { Cukup baik }\end{array}$ \\
\hline$C F I$ & $\begin{array}{l}\text { Comparative Fit Index (indeks kecocokan } \\
\text { komparatif) }\end{array}$ & $N F I \geq 0.90$ & Baik \\
\hline$N C P$ & $\begin{array}{l}\text { Noncentrality parameter (parameter tetap } \\
\text { yang berhubungan dengan } D F \text { ) }\end{array}$ & Semakin kecil & Semakin baik \\
\hline RMSEA & $\begin{array}{l}\text { Root mean square error of approximation } \\
\text { (sebagai kriteria untuk pemodelan struktur } \\
\text { kovarian) }\end{array}$ & $\begin{array}{l}R M S E A \leq 0.01 \\
0.01<R M S E A \leq 0.05 \\
0.05<R M S E A \leq 0.08\end{array}$ & $\begin{array}{l}\text { Sangat baik } \\
\text { Baik } \\
\text { Cukup baik }\end{array}$ \\
\hline
\end{tabular}

Jika model belum memenuhi kriteria kecocokan dengan data, model direspesifikasi secara post-hoc. Berdasarkan informasi diagnostik kecocokan dan pembenaran teoritis, model direvisi dan dicocokkan kembali dengan data untuk meningkatkan goodnessoffit model dan interpretabilitas model. Pendekatan untuk modifikasi model adalah menghapus parameter yang ada atau pemangkasan model (model trimming). Jalur dalam model yang tidak signifikan ( $\mathrm{p}>0.05$ ) menunjukkan muatan faktor yang salah.Keuntungan pemangkasan akan mendapatkan model yang lebih sederhana dengan derajat kebebasan lebih besar sehingga model lebih baik. Tahap selanjutnya menguji hubungan antara kondisi internal pertanian, sistem pertanian terintegrasi padi sawah dan ternak kerbau dan pengembangan wilayah di Kabupaten Humbang Hasundutan.

Pengaruh langsung diperiksa melalui nilai bobot regeresi standar (koefisien jalur) antara variabel laten. Pengaruh langsung signifikan jika nilai probabilitas bobot regresi standar adalah signifikan $(\mathrm{p}<0.05)$ atau dalam interval kepercayaan $95 \%$. Pengaruh tidak langsung diperiksa dengan memperhitungkan variabel bebas $\rightarrow$ variabel perantara mediator $\rightarrow$ variabel terikat diman nilai-nilai bobot regresi standar untuk kedua jalur dikalikan (nilai variabel bebas dan variabel perantara $\mathrm{x}$ nilai variabel perantara dan variabel terikat). Pengaruh tidak langsung harus lebih tinggi dari pengaruh langsung untuk menunjukkan pengaruh mediasi terjadi dalam pemodelan struktural. Artinya, nilai yang terkait pada variabel perantara harus lebih tinggi dari efek kausal. Variabel mediasi dianggap memiliki pengaruh untuk menambah/ mengurangi efek kausal dari variabel bebas terhadap variabel terikat. 
Jika variabel perantara tidak memberikan pergeseran yang mempengaruhi faktor utama $(\mathrm{p}>0.05)$, maka dikatakan mediasi tidak terjadi. Variabel ini lebih tepat dianggap sebagai variabel bebas karena tidak memberikan kontribusidalam analisis. Peninjauan nilai probabilitas perlu dilakukan setelah menghitung perkalian bobot regresi standar variabel bebas dan variabel perantara dengan bobot regresi standar variabel perantara dan variabel bebas. Pengaruh mediasi adalah signifikan hanya jika nilai probabilitas masing-masing bobot regresi standar signifikan $(\mathrm{p}<$ 0.05 ) atau dalam interval kepercayaan $95 \%$.

\section{Hasil}

Tingkat Efisiensi Sistem Pertanian Integrasi Padi Sawah dan Ternak Kerbau di Kabupaten Humbang Hasudutan. Biaya Produksi Sistem Pertanian Terintegrasi Padi Sawah dan Ternak Kerbau di Kabupaten Humbang Hasundutan. Berdasarkan hasil analisis data diperoleh biaya produksi usahatani padi sawah dan ternak kerbau dalam sistem pertanian terintegrasi di Kabupaten Humbang Hasundutan (Tabel 1).

Tabel.2. Biaya Produksi Usahatani Padi Sawah dan Ternak Kerbau dalam Sistem Pertanian Terintegrasi di Kabupaten Humbang Hasundutan.

\begin{tabular}{llllll}
\hline Uraian & $\begin{array}{l}\text { Usaha tani padi } \\
\text { sawah/ ha/ } \\
\text { tahun (Rp) }\end{array}$ & $\begin{array}{l}\text { Usaha ternak } \\
\text { kerbau/ tahun } \\
(\mathrm{Rp})\end{array}$ & $\begin{array}{l}\text { Non integrasi } \\
\text { (padi sawah }+ \\
\text { ternak) petani/ } \\
\text { tahun (Rp) }\end{array}$ & $\begin{array}{l}\text { Integrasi padi } \\
\text { sawah dan ternak } \\
\text { kerbau/ petani/ } \\
\text { tahun (Rp) }\end{array}$ & $\begin{array}{l}\text { Rasio biaya } \\
\text { integrasi } \\
\text { dan non } \\
\text { integrasi } \\
(\%)\end{array}$ \\
\hline $\begin{array}{l}\text { Biaya } \\
\text { Tetap (Rp) }\end{array}$ & $5.428 .199,30$ & $4.710 .500,00$ & $10.138 .699,30$ & $7.110 .959,44$ & 0,701 \\
$\begin{array}{l}\text { Biaya } \\
\text { Variabel }\end{array}$ & $2.493 .217,40$ & $5.431 .333,30$ & $7.924 .550,70$ & $6.369 .640,56$ & 0,804 \\
$\begin{array}{l}\text { Rp) } \\
\text { Biaya total }\end{array}$ & $7.921 .416,70$ & $10.141 .833,30$ & $18.063 .250,00$ & $13.480 .600,00$ & 0,746 \\
(Rp) & & & & \\
\hline
\end{tabular}

Sumber: Data Primer, diolah 2016.

Tabel 2 menunjukkan rata-rata total biaya untuk usahatani padi sawah/ ha/ tahun Rp. 7.921.416. 70 dan rata-rata total biaya ternak kerbau Rp. 10.141.833,30/petani/ tahun. Jika petani mengelola usahatani sistem integrasi padi sawah dengan ternak kerbau, maka rata-rata total biaya yang dikeluarkan petani/ tahun Rp. 13.480.600,00 dan jika petani mengelola usahatani dengan non integrasi maka petani mengeluarkan biaya Rp. 18.063.250/ tahun, dan untuk usahatani padi sawah dan ternak kerbau skala rumah tangga.

Penerimaan, Pendapatan Petani dan Efisiensi Sistem Pertanian Terintegrasi Padi Sawah dengan Ternak Kerbau. Sesuai hasil analisis data diketahui penerimaan, pendapatan petani dan tingkat efisiensi usahatani padi sawah dan ternak kerbau dalam sistem pertanian integrasi (Tabel 2).

Tabel. 3. Penerimaan, Pendapatan Petani dan Efisiensi Sistem Pertanian Terintegrasi Padi Sawah dengan Ternak Kerbau di Kabupaten Humbang Hasundutan.

\begin{tabular}{lcccc}
\hline Uraian & Penerimaan (Rp) & Total Biaya (Rp) & Pendapatan (Rp) & R/ C Ratio \\
\hline Usaha tani padi sawah & $23.323 .000,00$ & $7.921 .416,70$ & $15.401 .583,30$ & 2,9443 \\
Usaha ternak kerbau & $22.882 .534,25$ & $10.141 .833,30$ & $12.740 .700,95$ & 2,2563 \\
$\begin{array}{l}\text { Integrasi padi sawah dan } \\
\text { ternak kerbau }\end{array}$ & $33.425 .540,00$ & $13.480 .600,00$ & $19.944 .940,00$ & 2,4795 \\
$\begin{array}{l}\text { Non integrasi (Padi } \\
\text { sawah atau ternak }\end{array}$ & $39.205 .533,35$ & $18.063 .250,00$ & $21.142 .283,35$ & 2,1705 \\
\hline
\end{tabular}


Sumber: Data Primer, diolah 2017.

Tabel. 3. menunjukkan rata-rata penerimaan usahatani padi sawah Rp. 23.323.000,00/ha/ tahun, dan ternak kerbau Rp. 22.882.534,25/tahun. Rata-rata penerimaan sistem integrasi padi sawah dengan ternak kerbau Rp. 33.425.540,00/ tahun, penerimaan petani dengan sistem usahatani non integrasi adalah Rp. 39.205.533,35/tahun.

\subsection{Pengaruh Kondisi Internal Pertanian terhadap Sistem Pertanian Terintegrasi di Kabupaten Humbang Hasundutan}

Berdasarkan hasil analisis data diketahui kondisi internal pertanian berpengaruh langsung terhadap sistem pertanian terintegrasi padi sawah dengan ternak kerbau dan signifikan (dengan bobot regresi standar 0.52, $\mathrm{p}<0.001$ ), (Gambar 1)

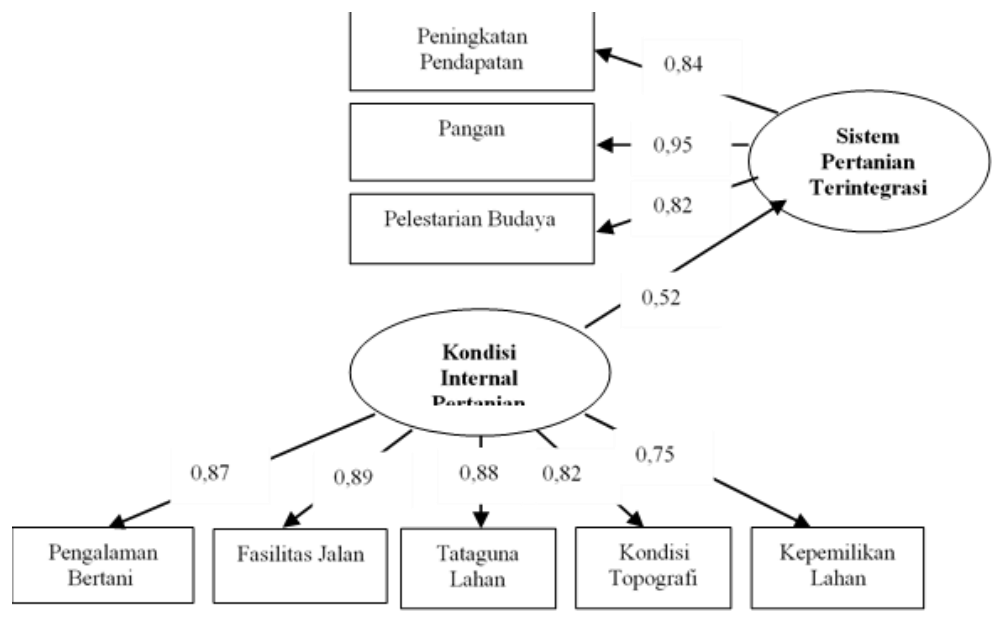

Gambar. 1. Pengaruh langsung kondisi internal pertanianterhadap sistem pertanian terintegrasi padi sawah dengan ternak kerbau.

\subsection{Pengaruh Kondisi Internal PertanianTerhadap Pengembangan Wilayah di Kabupaten Humbang Hasundutan}

Berdasarkan hasil analsis data diketahui kondisi internal pertanian memberikan pengaruh langsung terhadap pengembangan wilayah, namun tidak signifikan secara statistik (bobot regresi standar sebesar 0.24, $\mathrm{p}<0.001$ ), (Gambar 2).

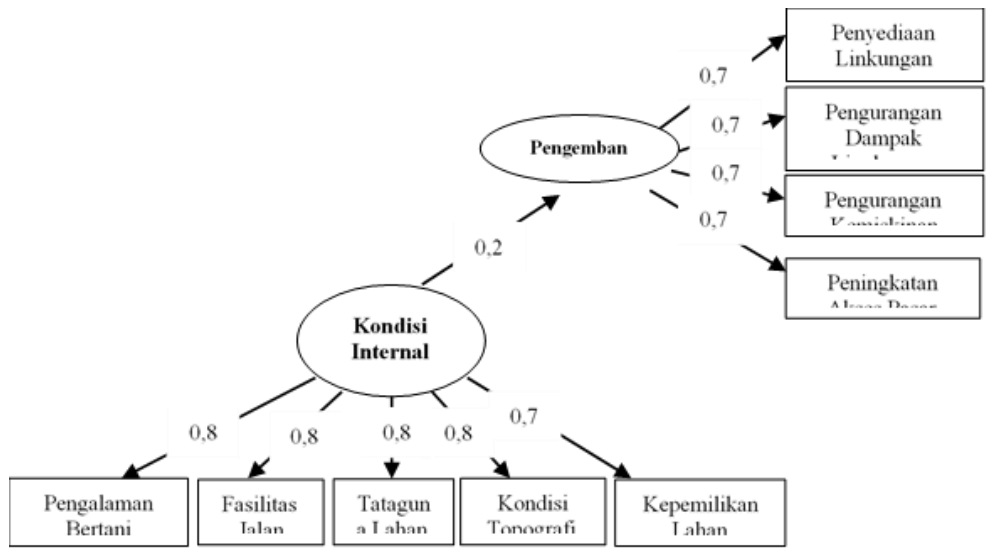


Gambar. 2. Pengaruh kondisi internal pertanian terhadap pengembangan wilayah di Kabupaten Humbang Hasundutan.

\subsection{Pengaruh Kondisi Internal Pertanian Terhadap Pengembangan Wilayah melalui Sistem Pertanian Terintegrasi Padi Sawah dengan Ternak Kerbau di Kabupaten Humbang Hasundutan.}

Berdasarkan hasil analisis data diketahui pengaruh tidak langsung kondisi internal pertanian terhadap pengembangan wilayah melalui sistem pertanian terintegrasi padi sawah dengan tenak sebesar $0.52 \times 0.53=0.28$, (Gambar 3).

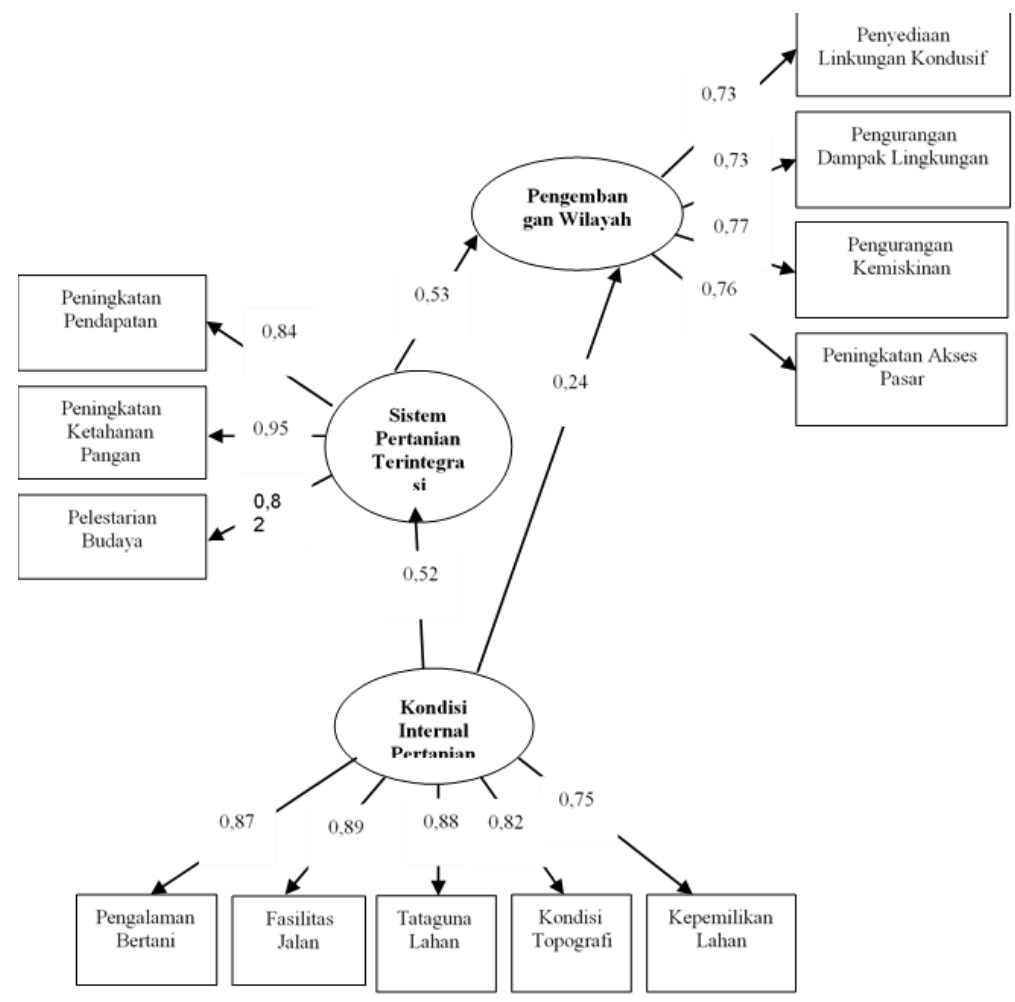

Gambar. 3. Pengaruh kondisi internal pertanian terhadap pengembangan wilayah melalui sistem pertanian terintegrasi padi sawah dengan ternak kerbau.

\section{Pembahasan}

\subsection{Tingkat Efisiensi Sistem Pertanian Integrasi Padi Sawah dengan Ternak Kerbau di Kabupaten Humbang Hasudutan.}

\subsection{Biaya Produksi Usahatani Sistem Pertanian Terintegrasi Padi Sawah dengan Ternak Kerbau di Kabupaten Humbang Hasundutan.}

Berdasarkan hasil analisis data sebagaimana pada Tabel 1 diketahui rata-rata total biaya untuk usahatani padi sawah Rp. 7.921.416.70/ ha/tahun, kemudian rata-rata total biaya ternak kerbau Rp. 10.141.833,30/petani/ tahun. Jika petani mengelola usahatani dengan sistem pertanian terintegrasi padi sawah dengan ternak kerbau, maka ratarata total biaya yang dikeluarkan Rp. 13.480.600,00/petani/tahun. Tetapi jika petani mengelola usahatani secara non integrasi maka petani akan mengeluarkan biaya Rp. 18.063.250/ tahun untuk usahatani padi sawah dan ternak kerbau dengan skala rumah tangga. Hal ini menunjukkan bahwa usahatani dengan sistem integrasi dapat menghemat biaya 
produksi yang dikeluarkan petani untuk setiap tahunnya yang ditunjukkan dengan rasio biaya 0,7463 . Penghematan biaya produksi ini akan meningkatkan cadangan modal yang dimiliki petani sesuai dengan hasil penelitian Poffenbarger [11].

\subsection{Penerimaan, Pendapatan Petani dan Efisiensi Usahtani Padi Sawah dan Ternak Kerbau dengan Sistem Pertanian Integrasi.}

Berdasarkan hasil analisis data sebagaimana Tabel 2 diketahui rata-rata penerimaan usahatani padi sawah Rp. 23.323.000,00/ha/ tahun, dan ternak kerbau Rp. 22.882.534,25/ tahun. Kemudian rata-rata penerimaan sistem pertanian terintegrasi padi sawah dengan ternak kerbau Rp. 33.425.540,00/tahun sementara penerimaan dengan sistem usahatani non integrasi Rp. 39.205.533,35/tahun.

Berdasarkan hasil analisis data pada Tabel 2, diketahui rata-rata pendapatan petani usahatani padi sawah Rp. 15.401.583,30 per ha/ tahun dengan R/C ratio 2,9443. Pendapatan usaha ternak kerbau Rp. 12.740.700,95 dengan $\mathrm{R} / \mathrm{C}$ ratio 2,2563. Kemudian rata-rata pendapatan petani dengan sistem integrasi padi sawah dan ternak kerbau adalah Rp. 19.944.940,00/tahun dengan $\mathrm{R} / \mathrm{C}$ ratio 2,4795, dan rata-rata pendapatan petani dengan sistem usahatani non integrasi Rp. 21.063.250,35/ tahun dengan $\mathrm{R} / \mathrm{C}$ ratio 2,1705.

Dengan demikian jika dilihat berdasarkan $\mathrm{R} / \mathrm{C}$ ratio, usahatani padi sawah lebih efisien dibandingkan usahatani ternak, dimana R/C ratio usahatani padi sawah 2,9443 > dari nilai R/C usaha ternak kerbau 2,2563. Tabel 2 menunjukkan sistem integrasi padi sawah dan ternak kerbau lebih efisien dibandingkan dengan non integrasi (usahatani dikelola secara parsial) dimana nilai R/C usahatani sistem integrasi padi sawah dan ternak kerbau 2,4795 $>$ dari $\mathrm{R} / \mathrm{C}$ ratio usahatani non integrasi.

Hasil penelitian ini sejalan dengan penelitian Ugwumba [12], Nurcholis[13] yang mengatakan bahwa sistem pertanian terintegrasi (SPT) mampu memperbaiki produktivitas usaha tani padi dan meningkatkan pendapatan petani. Produksi padi dapat meningkat dari 5-6 ton/hektarmenjadi 7,6-8 ton/hektar. Produktivitas cabai dapat ditingkatkandari $0,5 \mathrm{~kg} / \operatorname{tanaman}$ menjadi $0,7 \mathrm{~kg} / \operatorname{tanaman}$.

\subsection{Pengaruh Kondisi Internal Pertanian terhadap Sistem Pertanian Terintegrasi di Kabupaten Humbang Hasundutan.}

Berdasarkan hasil analisis data pada Gambar 1, diketahui kondisi internal pertanian berpengaruh langsung terhadap sistem pertanian terintegrasi padi sawah dengan ternak kerbau dan signifikan secara statistik (bobot regresi standar sebesar $0.52, \mathrm{p}<0.001$ ). Dengan demikian kondisi internal pertanian secara signifikan berpengaruh positif terhadap sistem pertanian terintegrasi padi sawah dengan ternak kerbau di Kabupaten Humbang Hasundutan.

Hasil analisis data pada Gambar 1, menunjukkan pengalaman bertani, yang merupakan salah satu prediktor bagi kondisi internal pertanian yang berkontribusi pada persepsi petani terhadap sistem pertanian terintegrasi padi sawah dengan ternak kerbau di Kabupaten Humbang Hasundutan. Hasil penelitian ini sejalan dengan penelitian Aryana[14] yang menyatakan semakin tinggi tingkat pengalaman petani, maka semakin mudah meningkatkan produksi untuk mencapai keuntungan maksimum. Hasil penelitian ini sesuai dengan penelitian Sanjaya [15], yang menyatakan salah satu indikator utama perefleksi variabel kualitas petani-peternak adalah pengalaman bertani yang berpengaruh terhadap penerapan usaha peternakan sapi, penerapan usaha tanaman pangan, dan penerapan usaha pengolahan limbah ternak sapi.

Demikian juga dengan fasilitas jalan sebagai indikator kondisi internal pertanian yang digunakan untuk distribusi produksi pertanian dan peternakan berkontribusi secara signifikan pada persepsi petani terhadap sistem pertanian terintegrasi padi sawah dengan ternak kerbau di Kabupaten Humbang Hasundutan. Hasil penelitian ini sejalan dengan penelitian Suroyo dan Handayani [16], yang memperlihatkan tingkat kesejahteraan petani Kabupaten Kulonprogo masih dibawah rata-rata, dimana faktor yang mempengaruhinya adalah kurangnya ketersediaan sarana dan prasarana agribisnis hulu-hilir seperti pemasaran dan kondisi jalan, sehingga menjadi hambatan utama bagi petani dalam meningkatkan produktivitasnya. Lebih lanjuthasil penelitian Muhajirin [17] dan Ishaq [18] menunjukkan bahwa faktor luas lahan garapan, jumlah tenaga kerja efektif, jumlah pupuk, jumlah pestisida, 
pengalaman petani dalam berusaha tani, jarak rumah petani dengan lahan garapan, dan sistem irigasi berpengaruh sangat nyata terhadap peningkatan produksi padi sawah.

Kabupaten Humbang Hasundutan berada pada ketinggian 330-2.075 meter diatas permukaan laut (mdpl) dengan iklim yang tergolongke dalam daerah tropis basah dengan 2 musim yaitu musim kemarau (bulan April sampai Agustus) dan musim hujan (bulan September sampai Maret). Suhu udara berkisar 17o- 29o C dengan rata-rata kelembaban udara (RH) sebesar 85,94\% dan jumlah rata-rata curah hujan adalah 234,26 mm. Jenis tanah yang banyak mengandung bahan organik dan memiliki keasaman yang relatif tinggi dengan rata-rata $\mathrm{pH}$ 5-6,5 mengindikasikan bahwa lahan pertanian di Kabupaten Humbang Hasundutan relatif subur. Dengan demikian hampir semua lahan di wilayah ini cocok untuk pengembangan komoditi padi sawah dan komoditi tanaman pangan lainya serta ternak kerbau bahkan kambingdan kuda. Kondisi topografi yang demikian ini berkontribusi secara signifikan pada persepsi petani terhadap sistem pertanian terintegrasi.

Disamping itu berdasarkan hasil analisis data diketahuiketerkaitan antara luas kepemilikan lahan pertanian dan jumlah ternak, dimana jika semakin luas lahan pertanian maka semakin banyak produksi pertanian dan peternakan yang dihasilkan. Kepemilikan lahan subsektor pertanian adalah penyumbang paling tinggi bagi pendapatan petani. Disamping karena usaha tani merupakan mata pencaharian pokok bagi masyarakat Kabupaten Humbang Hasundutan. Hasil penelitian ini sesuai dengan penelitian Hardiyanto [19] yang menyatakan bahwa kontribusi pendapatan dari berbagai cabang usaha tani sehingga tanaman pangan pertanian penyumbang terbesar pendapatan rumah tangga.

\subsection{Pengaruh Kondisi Internal Pertanian terhadap Pengembangan Wilayah di Kabupaten Humbang Hasundutan.}

Berdasarkan hasil analsis data diketahui bahwa kondisi internal pertanian memberikan pengaruh langsung terhadap pengembangan wilayah, namun tidak signifikan secara statistik (bobot regresi standar sebesar 0.24 , p < 0.001), sebagaimana pada Gambar 2. Berdasarkan hasil penelitian ini dapat dikatakan kondisi internal pertanian berpengaruh positif namun tidak signifikan terhadap pengembangan wilayah di Kabupaten Humbang Hasundutan.

Berdasarkan hasil analsis data sebagaimana pada Gambar 2, bahwa infrastuktur jalan merupakan lokomotif untuk menggerakan pembangunan ekonomi diwilayah pedesaan. Selain itu, infrastruktur merupakan pilar penentu kelancaran arus barang, jasa, manusia,uang dan informasi dari satu zona/ pasar ke zona/ pasar lainnya. Dalam menjual hasil panenpetani di Kabupaten Humbang Hasundutan bergantung pada tengkulak, yang berasal dari luar daerah. Apabila infrastruktur jalan dalam kondisi yang tidak baik maka arus transportasi barang akan terkendala. Apabila petani menjual sendiri hasil pertaniannya ke lokasi pemasaran, harga akan menjadi tinggi karena kondisi infrastruktur yang buruk ditambah dengan biaya transportasi yang tinggi. Hal yang sama diungkapkan Tarigan dan Syumanjaya [20] bahwa kualitas infrastruktur jalan berpengaruh positif terhadap sistem pemasaran hasil pertanian. Semakin baik kualitas infrastruktur maka semakin banyak petani yang memasarkan hasil-hasil pertaniannya secara langsung ke pasar.

Di samping itudesakan kebutuhan lahan untuk pelaksanaan pembangunan begitu cepat padalah luas lahan tidak bertambah dan terbatas. Lahan pertanian mempunyai nilai yang lebih rendah dibanding peruntukan lahan nonpertanian, akibatnya lahan pertanian mengalami perubahan peruntukan (konversi) ke lahan non-pertanian. Padahal lahan pertanian mempunyai nilai ekonomi sebagai penyangga kebutuhan pangan, juga berfungsi ekologi seperti mengatur tata air, penyerapan karbon di udara Dewi \& Rudiarto[21]. Manfaat dari adanya lahan pertanian seharusnya dapat dipertahankan, tidak untuk dialihfungsikan karena akan mengganggu ekosistem. Konversi lahan pertanian juga mengganggu kehidupan sosial ekonomi petani, perubahan sosial ekonomi yang dirasakan cenderung ke arah yang merugikan masyarakat petani. Hal yang sama diungkapkanHualin and Hua [22], yang melakukan penelitian di Huzhou, Zhejiang Province menyampaikan pengelolaan lahan tidak boleh terlepas dari kebijakan pemerintah, terutama karena keterbatasan lahan untuk sektor pertanian. Pemerintah membuat kebijakan penggunaan lahan untuk perumahan, fasilitas kesehatan dan pendidikan untuk mencegah pengurangan lahan pertanian. Pola perubahan tata guna lahan ini disebabkan karena pertumbuhan penduduk, kebijakan pemerintah pada sektor pertanian dan transmigrasi serta faktor sosial ekonomi lainnya. Akibatnya, lahan basah yang fungsi hidrologis dan ekologis semakin berkurang dan pada akhirnya meningkatkan peningkatan erosi tanah dan kerusakan lingkungan 
lainnya. Konsekwensi lainnya adalah berpengaruh terhadap ketidaktahanan pangan yang berimplikasi semakin banyaknya penduduk yang miskin.

\subsection{Pengaruh Kondisi Internal Pertanian terhadap Pengembangan Wilayah melalui Sistem Pertanian Terintegrasi di Kabupaten Humbang Hasundutan.}

Berdasarkan hasil analisis data diketahui pengaruh tidak langsung kondisi internal pertanian terhadap pengembangan wilayah melalui sistem pertanian terintegrasi padi sawah dengan ternak kerbau sebesar $0.52 \times 0.53=$ 0.28 , sebagaimana ditunjukkan Gambar 3. Total pengaruh dari kondisi internal pertanian terhadap pengembangan wilayah adalah $(0.28)+(0.24)=0.52$. Dengan demikian bahwa kondisi internal pertanian berpengaruh positif namun tidak signifikan terhadap pengembangan wilayah di Kabupaten Humbang Hasundutan melalui sistem pertanian terintegrasi padi sawah dengan ternak kerbau.

Hasil analisis data sebagaimana pada Gambar 3, meskipun peningkatan dilakukan pada prediktor-prediktor kondisi internal pertanian yang juga merupakan faktor penentu keberhasilan sistem pertanian teritegrasi, ternyata tidak secara signifikan meningkatkan pengembangan wilayah.Topografi lahan di Kabupaten Humbang Hasundutan yang beragam mulai dari lahan datar sampai lahan berbukit dan bergunung ternyata tidak memberikan kontribusi yang nyata pada persepsi petani terhadap pengembangan wilayah melalui sistem pertanian terintegrasi padi sawah dengan ternak kerbau. Hal ini dikarenakan petani menganggap bahwa lahan dengan topografi yang beragam tersebut tidak dapat dimanfaatkan sebagai lahan pertanian. Padahal lahan dengan beragam topografi tetap dapat dimanfaatkan sebagai lahan pertanian selama lahan tersebut tidak memiliki kendala tanah. Petani beranggapan bahwa kemiringan lereng merupakan faktor yang perlu diperhatikan, sejak dari penyiapan lahan pertanian, penanaman, pemeliharaan, pengambilan produk-produk serta pengawetan lahan. Lahan yang mempunyai kemiringan dapat lebih mudah terganggu/rusak, terutama jika derajat kemiringannya besar bahkan saat curah hujan tinggi dapat mengakibatkan tanah longsor.

Berdasarkan hasil analisis data diketahui bahwa fasilitas jalan memiliki kontribusi pada persepsi petani terhadap sistem pertanian terintegrasi padi sawah dengan ternak kerbau, namun tidak secara signifikan berkontribusi secara tidak langsung pada pengembangan wilayah. Padahal Prowse dan Chimhowu [23], menyatakan infrastruktur merupakan faktor kuncidalam mendukung program pengentasan kemiskinan termasuk dalam hal ini petani di pedesaan. Jika dilihat di negara-negara lain seperti di Vietnam, pesatnya penurunan angka kemiskinan tidak terlepas dari tingginya investasi untuk pembangunan irigasi dan jalan yang mencapai $60 \%$ dari total anggaran sektor pertaniannya pada akhir dekade 1990-an. Hal yang sama juga di India, pemerintah setempat membangun infrastruktur pedesaan untuk mengembangkan pertaniannya. Bahkan di Ethiopia yang pernah mengalami krisis pangan dan kelaparan pada pertengahan dekade 1980-an,perbaikan jalan di pedesaan dan peningkatan akses pasar bagi para petaninya mampu mengangkat tingkat kesejahteraan para petaninya.

Sehingga untuk menarik investor ke sektor pertanian maka pemerintah harus mempermudah aksesibilitas dan distribusi sarana produksi dan output pertanian, artinya sangat diperlukan infrastruktur yang memadai. Selama ini investasi pemerintah Kabupaten Humbang Hasundutan di bidang infrastruktur sangat minim, sehingga banyak jalan usahatani, jalan produksi, jaringan irigasi yang rusak. Untuk itu diperlukan kegiatan pembangunan dan atau rehabilitasi jalan usahatani, jalan produksi, jaringan irigasi tingkat usahatani, jaringan irigasi perdesaan, tata air mikro, irigasi tanah dangkal, sumur resapan, embung, waduk, dam parit, terasering dan lainnya, dalam rangka mengembangkan sistem pertanian diwilayah ini.

\section{Kesimpulan dan Saran}

\subsection{Kesimpulan}

Berdasarkan hasil pengolahan data dan pembahasan dapat disimpulkan: a) Sistem pertanian terintegrasi padi sawah dengan ternak kerbau lebih efisien dibandingkan dengan usahatani non integrasi, yang ditunjukkan dengan $\mathrm{R} / \mathrm{C}$ ratio sistem integrasi padi sawah dan ternak kerbau 2,4795> R/C ratio usahatani non integrasi, b) Kondisi 
internal pertanian berpengaruh langsung terhadap sistem pertanian terintegrasi padi sawah dengan ternak kerbau dan signifikan secara statistik dengan bobot regresi standar 0.52,p<0.001, artinya kondisi internal pertanian berpengaruh positif dan signifikan terhadap sistem pertanian terintegrasi padi sawah dengan ternak kerbau, c) Kondisi internal pertanian memberikan pengaruh langsung pada pengembangan wilayah, namun tidak signifikan secara statistik dengan bobot regresi standar $0.24, \mathrm{p}<0.001$, artinya kondisi internal pertanian berpengaruh positif namun tidak signifikan terhadap pengembangan wilayah, d)Kondisi internal pertanian memiliki pengaruh yang tidak langsung terhadap pengembangan wilayah melalui sistem pertanian terintegrasi padi sawah dengan ternak kerbau sebesar 0.28 , dan total pengaruh kondisi internal pertanian pada pengembangan wilayah sebesar 0.52 , artinya kondisi internal pertanian berpengaruh positif namun tidak signifikan terhadap pengembangan wilayah melalui sistem pertanian terintegrasi padi sawah dengan ternak kerbau.

\subsection{Saran}

Berdasarkan hasil pembahasan dan kesimpulan maka disarankan:

- agar pemerintah daerah melakukan pendidikan dan pelatihan untuk meningkatkan pengalaman petani untuk mengelola pertanian sistem integrasi antara padi sawah dengan ternak kerbau,

- agar pemerintah memperhatikan kelanyakan sarana dan prasarana penunjang pertanian, secara kusus fasilitas jalan untuk memudahkan petani dalam mengangkut hasil pertaniannya,

- agar pemerintah daerah berperan menyediakan bibit usahatani yang berkualitas dan terjangkau, disamping itu perlu dilakukan penyuluhan bagi petani/ peternak tentang beternak yang lebih baik,

- agar pemerintah daerah melakukan pendidikan/ pelatihan untuk meningkatkan kemapuan petani dalam mengelola dan mengembangkan usahataninya sehingga berdampak bagi peningkatan pendapatan petani dan pengembangan wilayah,

- agar pemerintah daerah berperan membantu petani untuk mendapatkan modal usahatani yang lebih fleksibel dan diharapkan peran pemerintah untuk menjaga stabilitas harga output hasil pertanian di Kabupaten Humbang Hasundutan.

\section{Ucapan Terimakasih}

Ucapan terimakasih disampaikan kepada LPDP Kementerian Keuangan RI Jakarta, yang telah membantu pembiayaan pelaksanaan penelitian ini.

\section{Referensi}

[1] Borisov B. 2015. Spatial planning in regional planning of agricultural lands and rural areas. Bulgarian Journal Of Agricultural Science. 21 (No 4) 2015, 751-756.

[2] Baransano Michael Albert, Eka Intan Kumala Putri, Noer Azam Achzani, dan Lala Kolopaking. 2016. Peranan sektor unggulan sebagai salah satu faktor dalam mengurangi ketimpangan pembangunan wilayah di Provinsi Papua Barat. Jurnal Perencanaan Wilayah dan Kota (Journal of Regional and City Planning) Vol. 27, No. 2, pp. 119-136.

[3] Setyowati Nuning 2012Analisis peran sektor pertanian di Kabupaten Sukoharjo. Jurnal SEPA: Vol. 8 No. 2.

[4] BPS Kabupaten Humbang Hasundutan Dalam Angka 2016. Doloksanggul.

[5] Nainggolan H L. 2016. Sistem pertanian terintegrasi berbasis padi sawah dalam rangka pengembangan wilayah di Kecamatan Lintong Nihuta Kabupaten Humbang Hasundutan. Laporan Hasil Penelitian. Lembaga Penelitian dan Pengabdian Masyarakat. Universitas HKBP Nommensen Medan.

[6] BijttebierJ, J Hamerlinck, S Moakes, N Scollan, J Van Meensel, L Lauwers 2016 Low-input dairy farming in Europe: Exploring a contextspecific notion. Agricultural Systemsjournal homepage: www.elsevier.com/locate/agsy Agricultural Systems 156 (2017) 43-51.

[7] Anugrah Iwan Setiajie, Sarwititi Sarwoprasodjo, Kedi Suradisastra, Ninuk Purnaningsih. 2014. Sistem pertanian terintegrasi-simantri: konse, pelaksanaan dan perannya dalam pembangunan pertanian di provinsi bali (Integrated Agriculture System (Simantri): Its Concept, Implementation, and Role in Agricultural Development in Bali Province) Forum Penelitian Agro Ekonomi, Volume 32 No. 2, Desember 2014: $157-176$. 
[8] Parma Putu Gede. 2014. Pengembangan model penguatan lembaga pertanian sebagai prime mover pembangunan kawasan daerah penyangga pembangunan (DPP) destinasi wisata Kintamani-Bali. Jurnal Ilmu Sosial dan Humaniora. Vol. 3, No. 1. April. Fakultas Ekonomi dan Bisnis Universitas Pendidikan Ganesha Singaraja.

[9] BPS Propinsi Sumatera Utara Dalam Angka. 2016. Medan.

[10] Shek DT and Yu L. 2014. Use of structural equation modeling in human development research. International Journal of Disabillity and Human Development;13:157-67.

[11] Poffenbarger Hanna, Georgeanne Artz, Garland Dahlke, William Edwards, James Russell, Harris Sellers, Matt Liebman. 2017. An economic analysis of integrated crop-livestock systems in Iowa, U.S.A. Journal homepage: www.elsevier.com/locate/agsy. Agricultural Systems 157 (2017) $51-69$.

[12] Ugwumba C O A, Okoh R N, Ike P C, Nuabuife E L C and Orji E C. 2010. Integrated farming system and its effect on farm cash income in Awka South Agriculatural Zone of Anabra State Nigeria. American-EurasianJournal Agricultural and Environt Science. Vol 8 (1).

[13] Nurcholis M dan Supangkat G. 2011. Pengembangan integrated farming system untuk pengendalian alih fungsi lahan pertanian. Prosiding. Seminar asional Budidaya Pertanian, Urgensi dan Strategi Pengendalian Alih Fungsi Lahan Pertanian. Bengkulu.

[14] Aryana A A N B, Budhi M K S dan Yuliarmi N N. 2016. Pengaruh karakteristik petani dan peran pendamping terhadap keberhasilan simantri di Kabupaten Badung. E-Jurnal Ekonomi dan Bisnis Universitas Udayana. 5 (4), 689-720.

[15] Sanjaya I G A M 2013 Efektifitas Penerapan Simantri dan Pengaruhnyaterhadap Peningkatan Pendapatan Petani-Peternak di Bali. (disertasi). Denpasar: Universitas Udayana, Program Pascasarjana.

[16] Suroyo B.T dan HandayaniW. 2014. Pengembangan kawasan agropolitan di Kabupaten Kulonprogo, Daerah Istimewa Yogyakarta. Jurnal Perencanaan Wilayah dan Kota. 25(3), 243-261.

[17] Muhajirin, Yusma Damayantidan Elwamendri. 2014. Analisis faktor-faktor yang mempengaruhi produksi usahatani padi sawah di Kecamatan Batang Asai Kabupaten Sarolangun. Jurnal Sosio Ekonomika Bisnis Vol 17. (1) 2014 ISSN 1412-8241.

[18] Ishaq Maulana, Agnes Tuti Rumiati, Erma Oktania Permatasari. 2017. Analisis Faktor-Faktor yang Mempengaruhi Produksi Padi di Provinsi Jawa Timur Menggunakan Regresi Semiparametrik Spline Jurnal Sains dan Seni ITS Vol. 6, No. 1, (2017) ISSN: 2337-3520 (2301-928X Print).

[19] Hardiyanto R. 2002. Strategi peningkatan kesejahteraan petani melalui optimalisasi pengelolaan DAS MIKRO dan pengembangan kapasitas kelompok di lahan kering marginal kawasan selatan Jawa Timur. Prosiding lokakarya pengembangan agribisnis berbasis sumberdaya lokal dalam mendukung pembangunan ekonomi kawasan selatan Jawa Timur. Pusat Penelitian dan Pengembangan Sosial Ekonomi Pertanian Bogor.

[20] Tarigan S D dan Syumanjaya R. 2013. Analisis pengaruh kualitas infrastruktur jalan terhadap harga-harga hasil pertanian di Kecamatan Dolok Silau. Jurnal Ekonomi dan Keuangan. Vol. 1 No.6.

[21] Dewi Nurma Kumala, Rudiarto Iwan. 2013. Impact of land use change in accelerating soil erosion in Indonesian upland area: a case of Dieng Plateau, Central Java - Indonesia. International Journal of AgriScience 2013 Vol.3 No.7

[22] Hualin Xie, Hua Lu. 2017. Impact of land fragmentation and non-agricultural labor supply oncirculation of agricultural land management rights. Land Use Policy 68 (2017) 355-364 journal homepage: www.elsevier.Com/locate/landusepol.

[23] Prowse M and Chimhowu A. 2007. Making agriculture work for the poor. Overseas Development Institute, Natural Resource Perspectives 111. 